\title{
Modelling and Dynamic Simulation of a Solar Vehicle for Track Events
}

\author{
${ }^{* 1}$ Onur Serin \\ *1 Department of Automotive Engineering, Kocaeli University, Kocaeli, Turkey
}

\begin{abstract}
World Solar Challenge (WSC) is a race held for solar powered vehicles from all around the world in every two years and multiple contestants from Turkey attend to this competition. The aim of this paper is to find a way of increasing the performance of vehicle during the qualifying lap of the race via modelling and dynamically simulating the solar vehicle. For this study, IPG/Carmaker software is used and a solar vehicle formed by two front and one rear wheel is modelled. Performance enhancer parameters including the vehicle design is selected and implemented to the model. Additional to vehicle model, race track is also modelled according to its physical features. According to gathered simulation results vehicle velocity and race duration is optimized. Vehicle is also tested on additional test cycles from literature and test outcomes are compared. Moreover, discussion between studies from literature is held.
\end{abstract}

Key words: Modelling, simulation, solar vehicle, vehicle dynamics

\section{Introduction}

With increasing global warming and vehicular regulations to produce cleaner cars, researches and projects over vehicles which are powered by clean ways such as solar power and electric power increase every day. Solar car is basically an electric vehicle which utilizes photovoltaic (PV) units to charge its battery [1]. Photovoltaic units in this concept are also known as solar cells or solar panels [2]. In other words, solar cells turn sunlight into electricity and this power source is used in order to run the vehicle. Solar vehicles are composed of three main electrical systems which are the battery pack, solar panel array and electric motor [2]. Solar cars are mainly grouped under green vehicle category since they produce zero emissions [1]. Unfortunately contemporary solar vehicle technology cannot be utilized as an everyday transportation device, nevertheless due to their improvement potential in future uses, researches on this area are widely supported by universities and main players of the automotive industry. Solar vehicle concept is formed via integration of several industries such as aerodynamics, electronics, alternative energy sources and automotive [3]. Mainly this study is done in order to observe the behavior of a designed solar vehicle which is designed by a Turkish university team to compete in World Solar Challenge. Prior to going in details of the study, concept of World Solar Challenge will be introduced. World Solar Challenge is one of the best established and highest participant attracting races in the World. Many university teams along with some corporate teams, such as Toyota and Honda, are among contestants of this international race [4]. Qatar University, Iowa State University, University of Malaya are some of the international participants of the race. In Turkey there are several teams from university who participate or to aim for participating to this race. Istanbul Technical University, ARIBA team is one of the examples from Turkey's national solar vehicle university teams. The first World Solar

*Corresponding author: Address: Institute of Natural and Applied Sciences, Kocaeli University, Kocaeli / TURKEY. E-mail address: serinonur@gmail.com 
Challenge is organized in 1987 and won by Sunraycer solar team from General Motors. The race is still organized every two years [5]. World Solar Challenge can also be considered as the World's biggest solar car race in terms of track length since it covers 3000 kilometers (1900 miles) distance from Darwin to Adelaide, Australia [6]. Mapped race track can be observed in Figure 1, below.

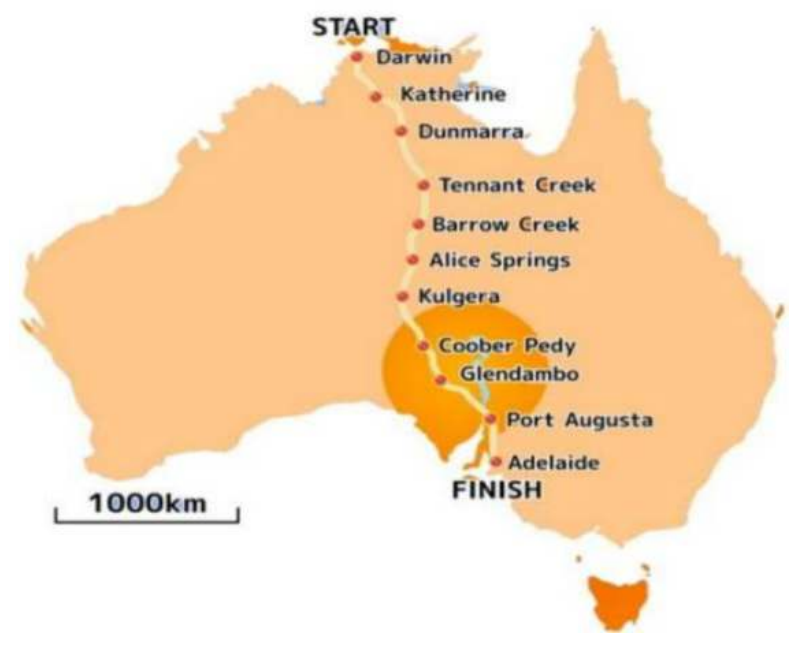

Figure 1. World Solar Challenge Race Track [7]

So this challenge can be summed as a race which gathers several universities and companies around the World in order to show their fascinating vehicle body shapes, designs, construction styles and components along with their marvelous workmanship [8]. There are multiple driving restrictions within the World Solar Challenge such as; driving time is limited between 8:00 am and 5:00 pm. Moreover there are several points on the route that are checkpoints where it is compulsory for the vehicle to stop for 30 minutes [7]. In addition to driving requirements, there are several design criteria for race preparation as well. In this study good aerodynamics, benefitting the maximum amount of solar energy, an electrical system with high efficiency criteria are the most focused ones. Design and production phases can be summarized as long and harsh durations which are formed by long periods of optimization, research and development.

The aim of this paper is to find a way of increasing the performance of solar race vehicle during the qualifying track race of the challenge via modelling on MATLAB/Simulink and dynamically simulating the solar vehicle on IPG/CarMaker software. This research paper is gathered by many sections such as Material and Method, in which the making process of the study is introduced. Reached outputs are shared in Results section. Remaining of the paper is formed by Discussion and Conclusion sections.

\section{Materials and Method}

For the race simulation a solar vehicle with two front and one rear wheel is designed, modelled and simulated. Along with the design and modeling processes optimization of vehicle mass, front area and aerodynamic resistance coefficient are all studied. Starting values of these variables and their post optimization values can be examined in Table 1. 
Table 1. Solar Vehicle Variables Before and After Optimization

\begin{tabular}{ccc}
\hline & Before Optimization & After Optimization \\
\hline Unladen Mass $[\mathrm{kg}]$ & 183 & 156 \\
\hline Mass with Driver $[\mathrm{kg}]$ & 263 & 236 \\
\hline Front Area $\left[\mathbf{m}^{2}\right]$ & 0.876 & 0.76 \\
\hline Aerodynamic Resistance Coefficient & 0.12 & 0.1 \\
\hline
\end{tabular}

With utilization of listed and unlisted parameters, necessary dynamic calculations are held and a vehicle design suitable for both race requirements and performance needs is achieved. Design criteria and acquired variable values for some parameters are presented in Table 2.

Table 2. Parameter Values and Design Limits

\begin{tabular}{ccc}
\hline & Target Value & Calculated Value \\
\hline Braking Distance (with $\mathbf{5 0} \mathbf{~ k m} / \mathbf{h}$ velocity) & $25[\mathrm{~m}]$ & $19.6[\mathrm{~m}]$ \\
\hline Braking Distance (with $\mathbf{3 5} \mathbf{~ k m}$ velocity) & $12.5[\mathrm{~m}]$ & $9.4[\mathrm{~m}]$ \\
\hline Rollover Limit & $0.6 \mathrm{~g}$ & $0.48 \mathrm{~g}$ \\
\hline
\end{tabular}

After finalizing the design process, the vehicle is modelled on MATLAB/Simulink and simulated on IPG/CarMaker. IPG/CarMaker is a software used to simulate and analyze the behavior of a vehicle on a previously modelled parkour. With the help of software, simulation results can be studied easily. Result of each simulation is provided in graphs which show alterations over selected vehicle parameter and also represented in three dimensional visual aids. For simulating the solar car, a three wheeled solar electric vehicle is needed on the software. Unfortunately due to general usage of the software for vehicles with four wheels, a custom vehicle design with three wheels is needed to be created. For this process transferring several parameters of the car is required. For instance weight and coordinates of every sprung mass along with weight and coordinates of every unsprung mass, spring and damper hardness values, steering box gear ratio, brake system parameters and engine torque efficiency curve. Created simulation helps to control and observe the vehicle in various ways.

Moreover, the vehicle can be controlled via a previously selected speed profile or a speed controller as well as an artificial driver. By defining an artificial driver, the vehicle can be driven as if there is a real life driver who is controlling the car. Defining process of an artificial driver yields observing the vehicle behavior under different drive properties such as defensive, normal and aggressive drive profiles. From drive simulations of these profiles many feedbacks such as steering control, braking behavior, and accelerator pedal position can be achieved. Behavior of an artificial driver can be summarized as deciding the route to follow, steering control, deciding the car speed and using pedals. World Solar Challenge is formed by two separate stages. The first one is the track race in which participant rankings for second stage are determined. In second stage, participants drive their solar cars through 3000 kilometers in seven days [3]. Since curve diameters of the track are not known exactly, scaled image of the track is fed to an image recognition software and coordinates of each turn is calculated and implemented on the software. After implementation of each curve on IPG/CarMaker a dummy race track is acquired. Representative view of track stage from IPG/CarMaker can be seen in Figure 2. Also modelled solar vehicle can be observed in Figure 3. 


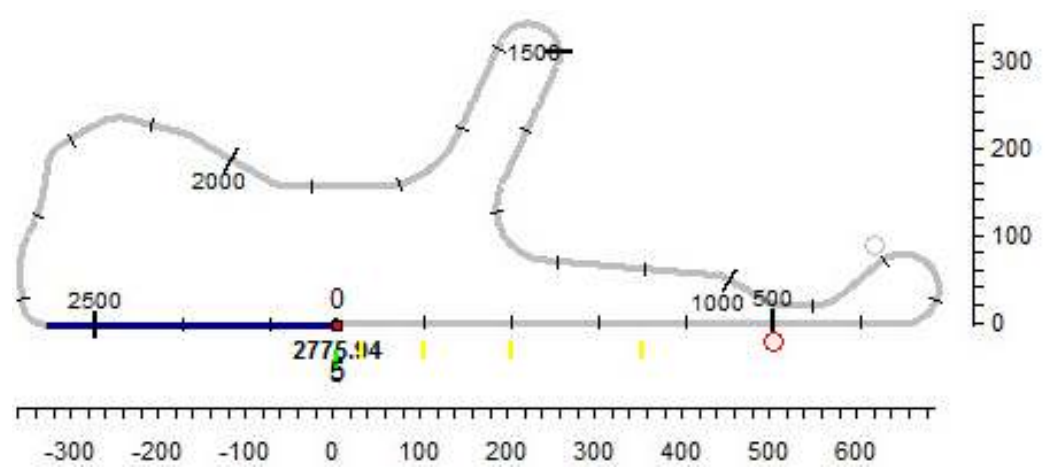

Figure 2. Representation of Track in IPG/CarMaker

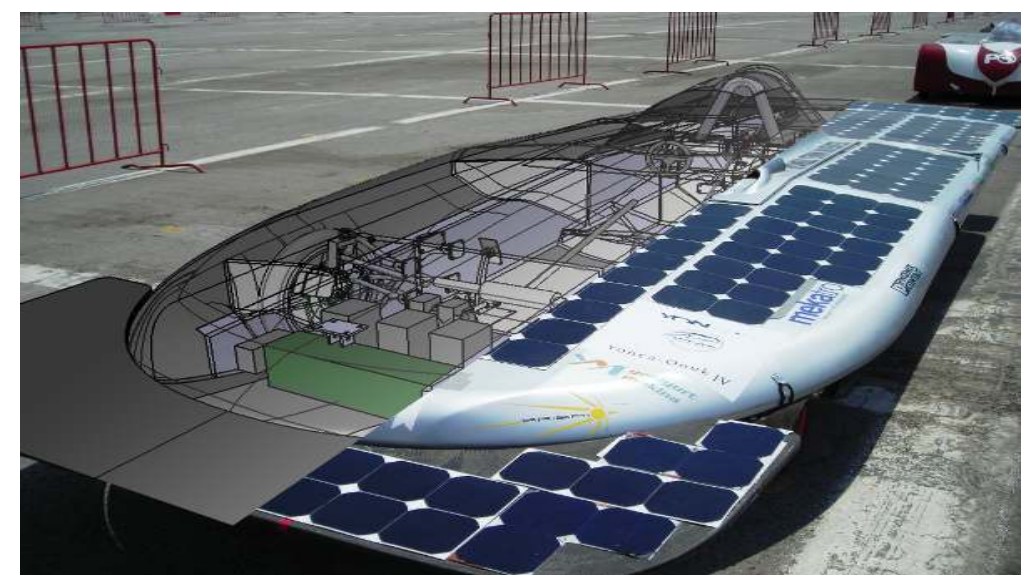

Figure 3. Modelled Solar Vehicle

After completion of modelling and preparation of simulation processes, the vehicle behavior is simulated on the software and results are achieved for various scenarios. Acquired outputs are given in following section, Results.

\section{Results}

Simulations for this research are done in two separate stages. The first one shows observation of solar vehicle reaction against standard maneuvers. Second stage monitors the state of vehicle during track races.

\subsection{Standard maneuvers}

\subsubsection{Straight lane braking test}

Among the requirements given in challenge rule book, the car is expected to stop within a limited range as well as satisfying braking acceleration conditions at a certain velocity [9]. To apply stated rule, modelled solar vehicle is accelerated until given velocity on a straight lane and then full braking power is applied in order to observe acquired braking distance and distributed load during breaking. Straight lane braking test at $50 \mathrm{~km} / \mathrm{h}$ speed can be observed in Figure 4. 


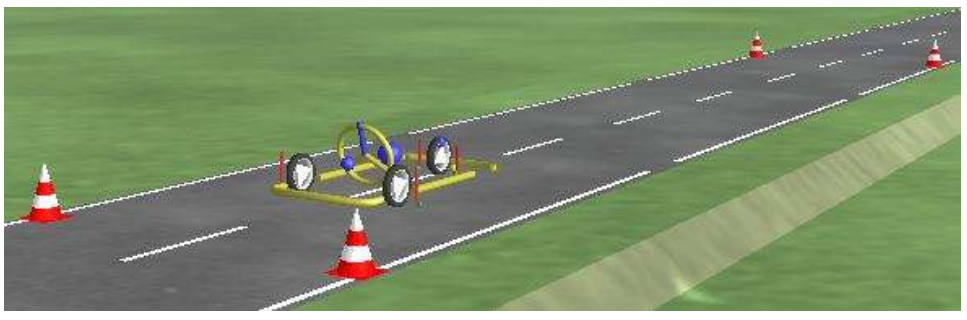

Figure 4. Straight Lane Braking Test at $50 \mathrm{~km} / \mathrm{h}$

In Figure 5 load distribution from rear wheels to front wheels after braking test on a straight lane can be seen.

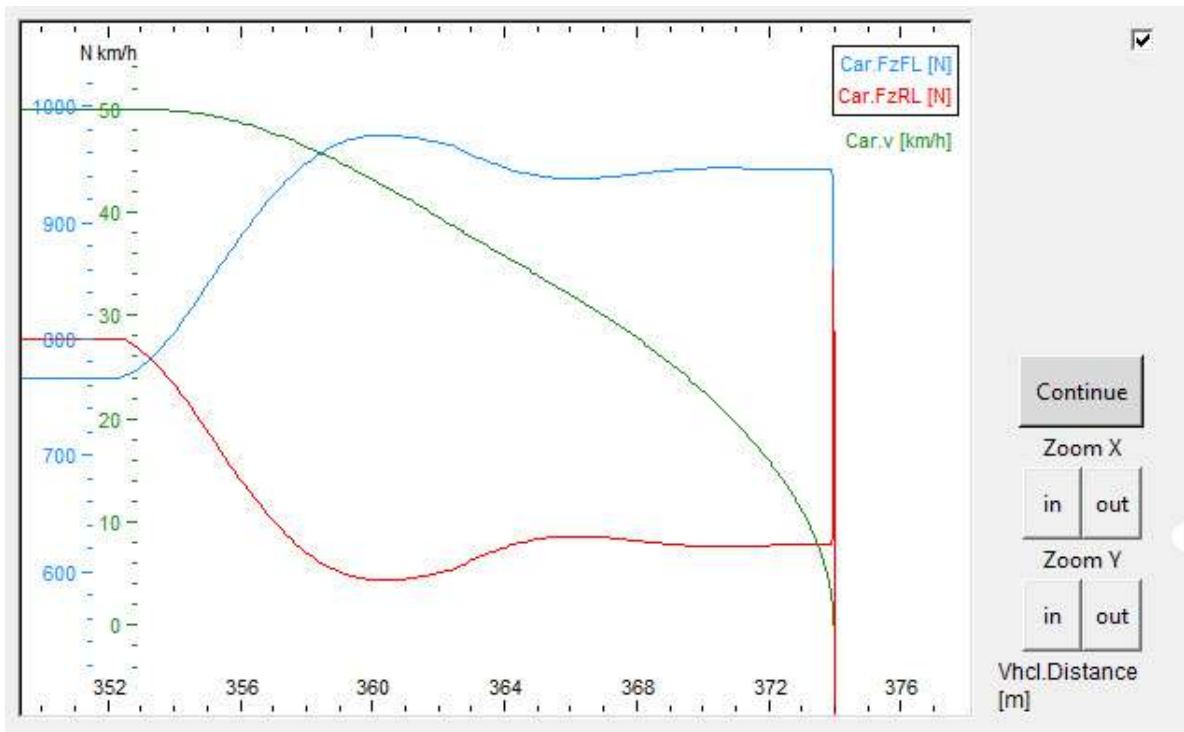

Figure 5. Load Distribution after Straight Lane Braking Test

In this figure a load distribution graph for two speed values is given. For $50 \mathrm{~km} / \mathrm{h}$ constant speed value it is seen that braking is applied 350 meters after start point and the vehicle succeeded stopping only after 21.5 meters. Also for $35 \mathrm{~km} / \mathrm{h}$ constant speed braking is applied after cruising for 250 meters and the car achieves to fully stop only after 11 meters.

\subsubsection{Constant radius turning test}

Constant radius turning test is carried in order to find the maximum lateral acceleration magnitude which the vehicle can endure while covering the curve without losing its stability. Virtual test is held in a turn with 50 meters constant radius. Model of the turn can be seen in Figure 6. In this test car is moved in clockwise rotation with $62 \mathrm{~km} / \mathrm{h}$ velocity. Detailed representation of lateral acceleration, vehicle velocity and load decrease over inner wheels due to load transfer is given in Figure 7. From simulations it is interpreted that, the maximum value of lateral acceleration which the vehicle can endure without rolling over is $0.6 \mathrm{~g}$. Comparison of limit values, calculated values and post simulation values are given in Table 3 . 


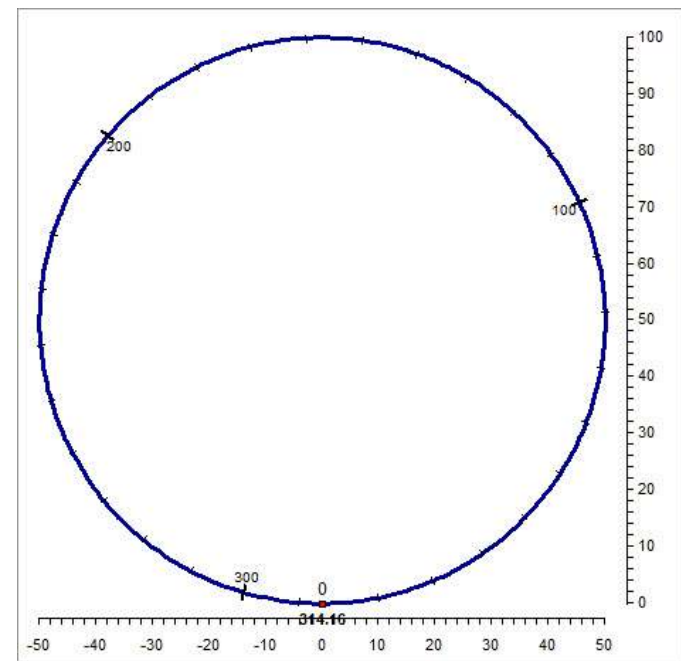

Figure 6. $50 \mathrm{~m}$ Constant Radius Turning Test Model

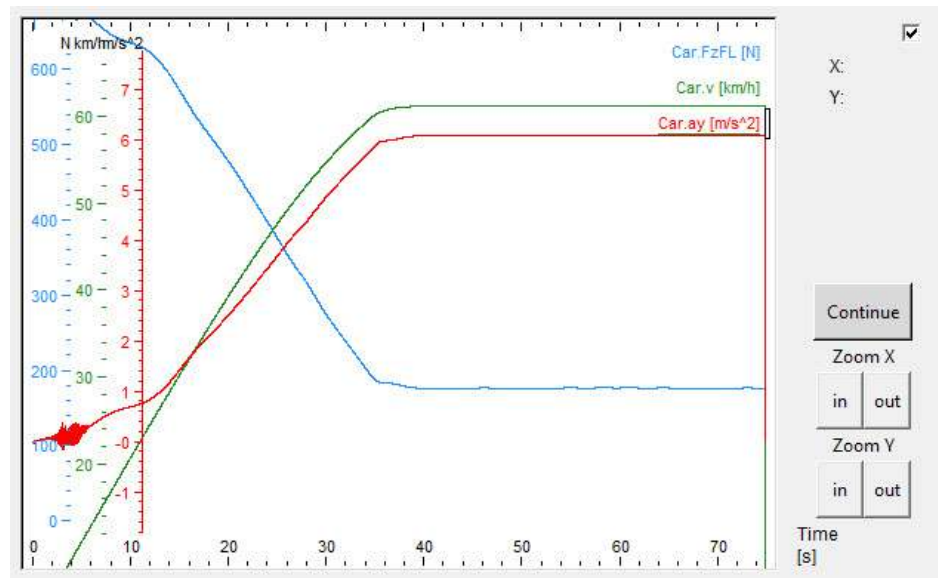

Figure 7. Constant Radius Test Results

Table 3. Comparison of Values after Simulation

\begin{tabular}{cccc}
\hline & Target Value & Calculated Value & Post Simulation Values \\
\hline Braking Distance (with 50 km/h velocity) & $25[\mathrm{~m}]$ & $19.6[\mathrm{~m}]$ & $21.5[\mathrm{~m}]$ \\
\hline Braking Distance (with 35 $\mathbf{~ m m} / \mathbf{h}$ velocity) & $12.5[\mathrm{~m}]$ & $9.4[\mathrm{~m}]$ & $11.0[\mathrm{~m}]$ \\
\hline Rollover Limit & $0.6 \mathrm{~g}$ & $0.48 \mathrm{~g}$ & $0.6 \mathrm{~g}$ \\
\hline
\end{tabular}

During these studies dropping of wheel load less than $15 \mathrm{~kg}$ case is assumed while calculating the roll over point of vehicle. Assuming wheel load larger than $0 \mathrm{~kg}$ is done in order to consider some physical conditions such as cross winds, bumps and holes in the road and to stay in the safe side. Differently from theoretical calculations, during simulations a driver model with reaction times is included hence results of simulations come out a little bit higher than the results found in theoretical calculations. Nevertheless analysis results satisfy limits set by rule book. 


\subsubsection{Slalom test}

Addition to previous tests, for further check the vehicle performance a slalom drive test is simulated on software. In this test the vehicle is expected to successfully complete a route which is formed by multiple pins placed in every 18 meters. Three dimensional representation of this track can be seen in Figure 8. During test it is seen that the modelled vehicle can easily cover the track with 65 $\mathrm{km} / \mathrm{h}$ while only experiencing $6 \mathrm{~m} / \mathrm{s}^{2}$ lateral acceleration. Simulation outputs can be observed in Figure 9.

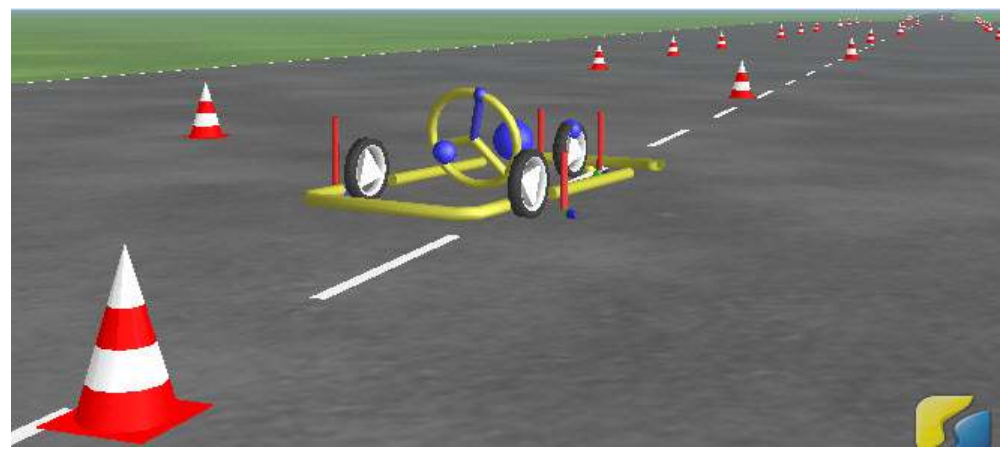

Figure 8. Slalom Test Track

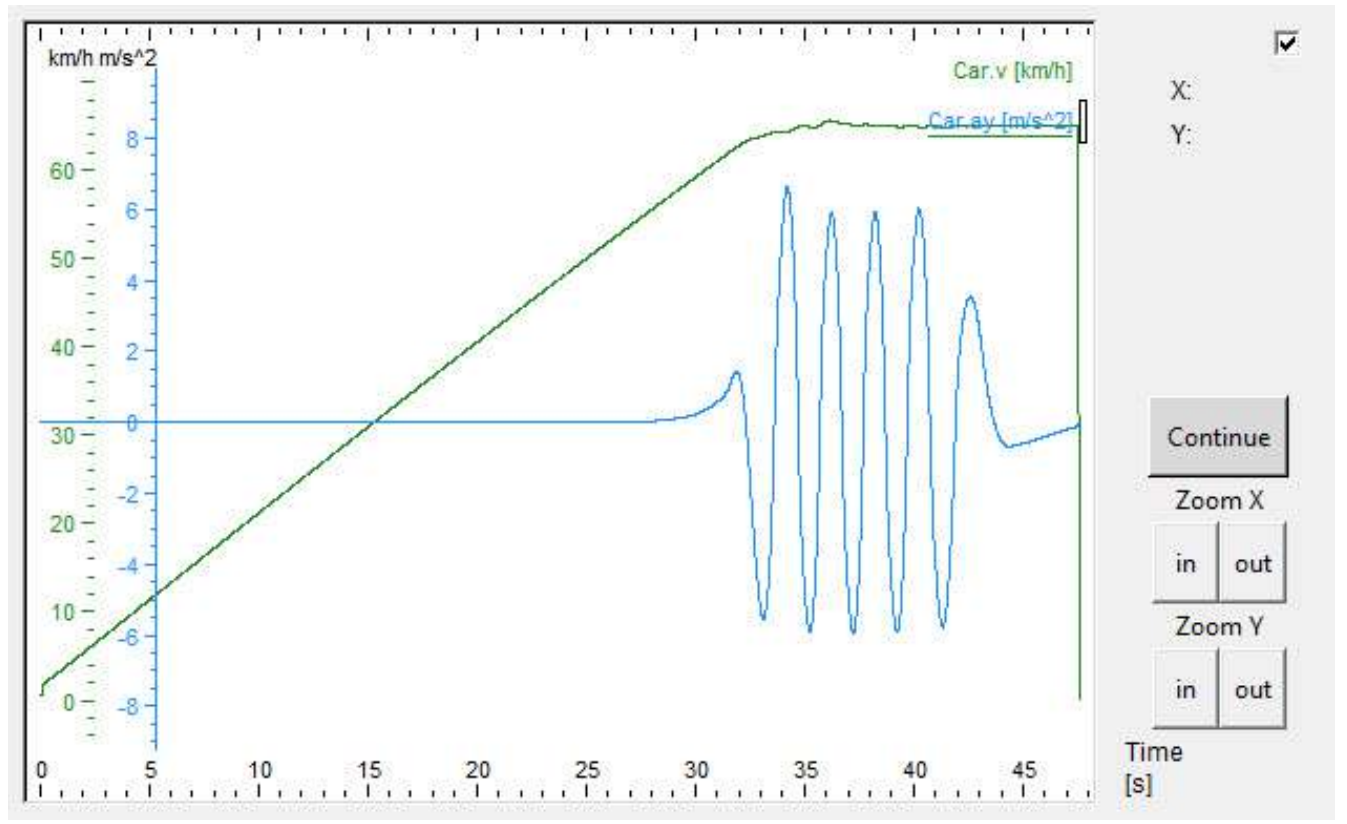

Figure 9. Slalom Test Results

\subsubsection{Braking analysis during turns}

Brake analysis during turns are held to see vehicle in two different vehicle conditions. The first one is for observing roll over stability of the vehicle. Second examination is done in order to study starting moment of braking action and its following one second interval. While studying that one 
second interval variables such as yaw rate, diversion from lateral trajectory can be inspected as well. During analysis stability loss only in maximum braking and roll over concepts are examined via simulations. Listed variables for vehicle drive are not additionally examined. Moreover, the car is accelerated in a straight lane track and tried to be stopped in the middle of a turn with 50 meters radius. During this attempt it is observed that the vehicle only experiences a very low profiled rolling over behaviour. Geometry benefitted for testing the braking attempt during a turn is given in Figure 10. Simulation view of low profile roll over behaviour and under steering attempt can be seen in Figure 11.

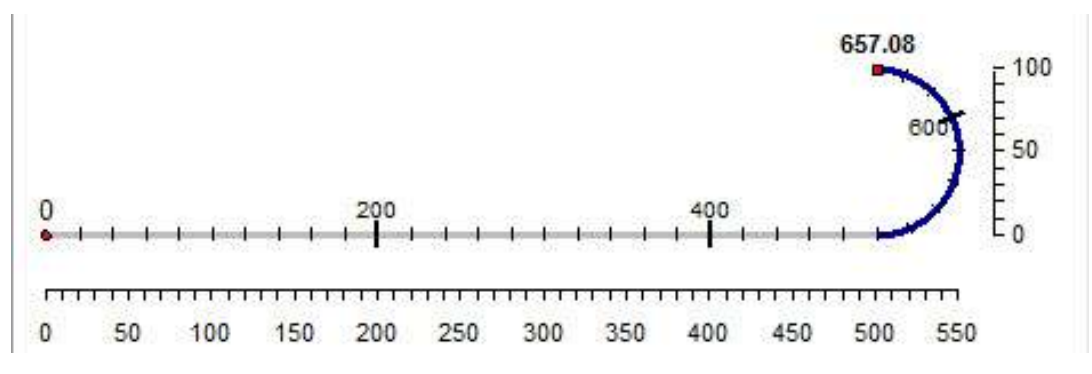

Figure 10. Turn Geometry

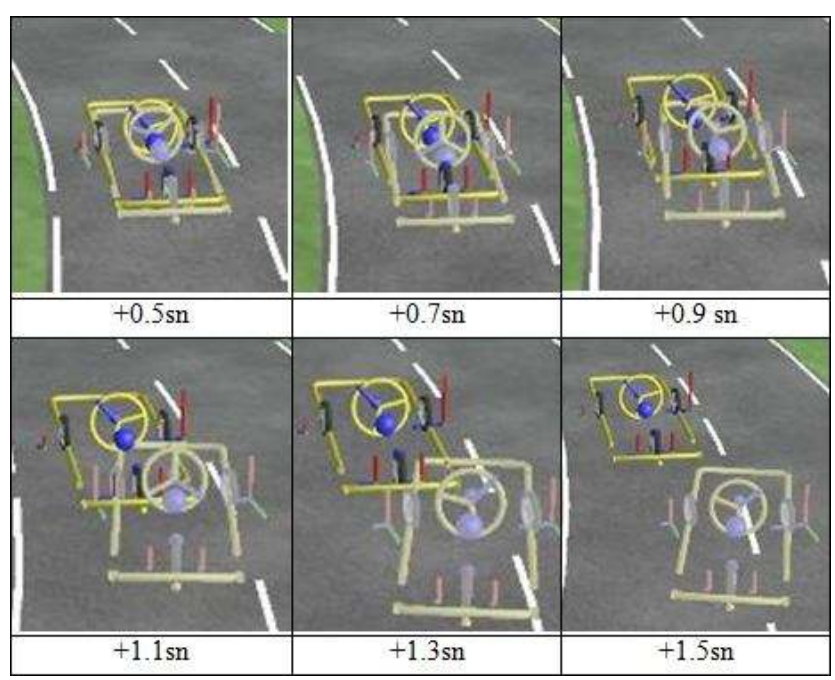

Figure 11. Braking in Turn

\subsection{Track constraints and related outcomes}

In this sub-section analysis over the track explained in previous section is presented. At this point it is important to emphasize that carrying out studies over a track provides information about time. So according to acquired results in order to minimize track time and maximize vehicle performance some variable and/or parameters can be revisited. Additionally data retrieved from this analysis yields technical optimization opportunities over vehicle drive dynamics. At this step, every turn inside the track is covered while maximum lateral acceleration effecting the car so that the minimum track duration can be achieved. In Figure 12 velocity alterations during track race simulation can be seen. From the figure it can be stated that between start and finish points the 
highest velocity which the vehicle reaches is $103 \mathrm{~km} / \mathrm{h}$. Also the shortest track completion time is calculated as 2 minutes 20 seconds.

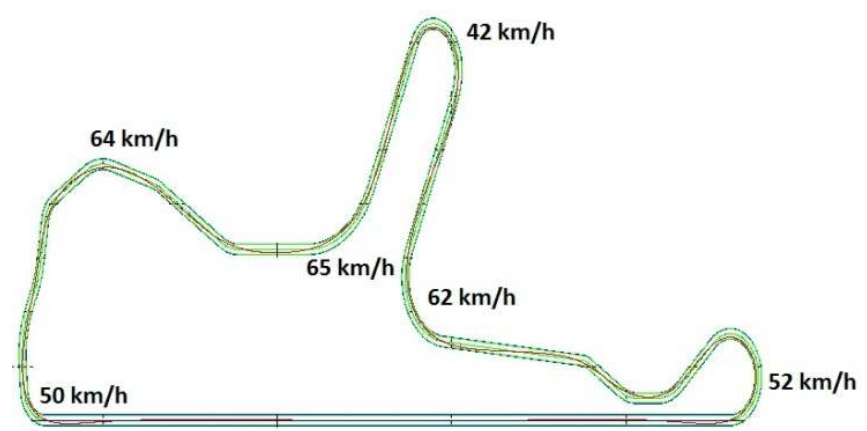

Figure 12. Velocity Values from Track Race Simulation

\section{Discussion}

In literature there are several papers written on solar cars and performance optimization of solar electric vehicles. A study done by Wright [8] in 1997 focuses on energy management optimization of a solar race car. This paper, too, works on a World Solar Challenge participant vehicle and tries to acquire an energy optimization strategy. As a result Wright [8] proposes maintaining constant speed throughout the whole track by stating that velocity peaks above drive speed lead to energy waste.

Another sample from literature is held by Taha et al. [1] in 2008 on energy management of a solar vehicle. Researchers of this study try to achieve maximizing vehicle energy while setting design parameters. At the end of the paper it is concluded that in order to achieve the best system optimization battery power should be managed properly. In other words selecting right weight and capacity for battery enhances overall solar car performance.

In 2016 Elshafei et al. [7] aim to optimize solar car performance by making the most use of solar energy. To elaborate, researchers propose using mandatory stops during daytime when the solar energy is maximized and utilization of saved solar energy at the end of day when solar energy is not as powerful as the day time. Researchers also try to maximize speed between landmarks.

In this new research, the analysis is focused on track race part of World Solar Challenge since ranking in the first stage effects vastly over the remaining part of the challenge. For this goal a three wheeled solar car is modelled on MATLAB/Simulink and simulated on IPG/CarMaker. During studies, track is also modelled in details. After simulations and optimization processes track completion time is minimized as 2 minutes and 20 seconds. Prior to optimization step, the vehicle could cover the track about three minutes so it can be interpreted that there is a $22 \%$ enhancement in terms of track time.

\section{Conclusions}

Especially in recent years drive dynamics simulations are vastly done both in commercial vehicle 
industry and in non-commercial research fields for providing an insight over vehicle performance and possible performance enhancement opportunities. Testing vehicles in virtual environments utilizes usage of both economic and material resources on design, prototype and vehicle licensing processes. Studies like this research may also come in handy while examining more vital projects or expensive designs. For further studies researcher aims to upgrade solar vehicle performance for World Solar Challenge in order to rank better in the competitions.

\section{References}

[1] Z. Taha, R. Passarella, J. M. Sah, N. Bin ve N. A. Rahim, "A Review on Energy Management system of Solar Car» Proceedings of the 9th Asia Pasific Industrial Engineering \& Management System Conference (APIEMS 2008), Bali, Indonesi, 2008.

[2] A. Mills ve E. Stumpges, «The American Solar Challenge 2012» IEEE Potentials, vol. 32, no. 2, pp. 10-16, 2013.

[3] A. O. Onol, O. Atabay, A. Icke ve O. Serin, «Longitudinal Dynamics of a Solar Electric Vehicle» International Journal of Vehicle Design» vol. 73, no. 1-3, pp. 136-156, 2017.

[4] N. Alnunu, S. Said, S. Al-Sharman, A. Al-Ibrahimi, A. AbdulAziz, M. Al Hellabi, F. Touati, S. Ghani, E. S. Mahdi ve M. Benammar, «Design of Qatar University's First Solar Car for Shell Eco-Marathon Competition» First International Conference on Renewable Energies and Vehicular Technology (REVET 2012), Hammamet - Tunisia, 2012.

[5] J. Zhao, F. Yun, G. Zhang, D. M. Roche, S. R. Wenham ve M. A. Green, «20000 PERL Silicon Cells for the '1996 World Solar Challenge' Solar Car Race» Progress in Photovoltaics: Research and Applications» vol. 5, pp. 269-276, 1997.

[6] S. Tamura, «Teijin's Advanced Carbon Fiber Technology Used to Build a Car for the World Solar Challenge» Reinforced Plastics» vol. 60, no. 3, pp. 160-163, 2016.

[7] M. Elshafei, A. Al-Qutub ve A. W. Saif, «Solar car optimization for the World Solar Challenge»13th International Multi-Conference on Systems, Signals \& Devices (SSD), Leipzig, Germany, 2016.

[8] G. S. Wright, «Optimal Energy Management for Solar Car Race» 39th Midwest Symposium on Circuits and Systems, Ames, IA, USA, USA, 1997.

[9] World Solar Challenge Committee, «Regulations». 